African Journal of Biomedical Research, Vol. 10 (2007); 59 - 65

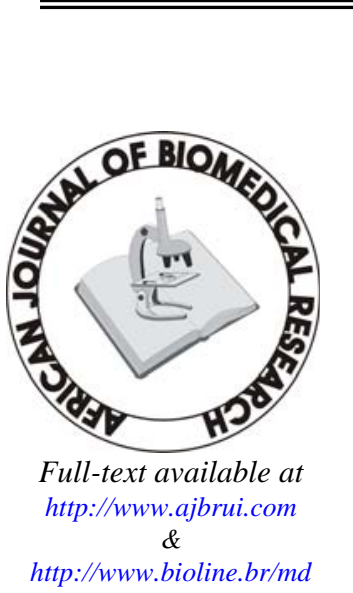

Received:

November, 2006

Accepted (Revised):

December, 2006

Published

January, 2007
Full Length Research Article

\section{Interaction and Enhancement of the Toxic Effects of Sodium Arsenite and Lead Acetate in Wistar Rats}

\author{
*Oyeronke A. Odunola ${ }^{1}$; Kazeem A. Akinwumi ${ }^{1,2}$; \\ Babatunde Ogunbiyi ${ }^{1}$ and Oladimeji Tugbobo ${ }^{1}$ \\ ${ }^{1}$ Cancer Research and Molecular Biology Laboratories, Department of \\ Biochemistry, College of Medicine, University of Ibadan, Ibadan. Nigeria. \\ ${ }^{2}$ Department of Biochemistry, College of Natural and Applied Sciences, \\ Bells University of Technology, Ota. Nigeria.
}

\section{ABSTRACT}

Continuous exposure of humans to arsenic through long-term ingestion of contaminated drinking water and its attendant health problems has been widely reported. It is also known that arsenic interact with other substances, metals inclusive thereby potentiating its effects or vice versa. In this study, we examined the effects of sodium arsenite (SA) and lead acetate (LA) in wistar rats. Sodium arsenite $(2.5 \mathrm{mg} / \mathrm{kg}$ bd.wt) and lead acetate $(14 \mathrm{mg} / \mathrm{kg}$ bd.wt) were fed to rats by gavage for fourteen consecutive days alone or simultaneously. Control rats were fed with distilled water. Clastogenic effects were observed in the bone marrow cells using the micronucleus assay. In addition, serum activities of gamma glutamyl transferase $(\gamma$-GT), alkaline phosphatase (ALP), alanine amino transferase (ALT) and aspartate amino transferase (AST) were monitored . The findings indicate that SA and LA separately induced the formation of micronucleated polychromatic erythrocytes (mPCEs) in the bone marrow of the rats significantly $(\mathrm{P}<0.05)$ by about 9 and 8 folds respectively. When fed simultaneously, the induction was about 22 folds as compared with the negative control group. SA significantly induced the serum activity of all the enzymes while LA significantly induce the activity of only $\gamma$-GT and ALP $(P<0.05)$. Simultaneous feeding of SA and LA also markedly induced the activity of all the enzymes in the serum. Mild infiltrative haemorrhage was observed in the lungs of rats exposed to the two compounds. This study underscores the enhanced toxic effect of combined or simultaneous exposure to toxic substances.

(Afr. J. Biomed. Res. 10: 59 - 65 , January 2007)

Keywords: arsenite, lead acetate, gamma glutamyl transferase, alkaline phosphatase, alanine amino transferase and aspartate amino transferase.

*Address for Correspondence: e-mail: ronodunola@yahoo.com 


\section{INTRODUCTION}

Arsenic (As) and lead (Pb) are wellrecognized environmental toxicants (Elias, 1985; Abernathy, et al, 1999; Poma, et al 2003). Exposure to As especially through the consumption of contaminated well water has been associated with skin lesions, certain forms of cancers and other non-cancer health effects such as neurological disorders and impaired cognitive development in children (Valentine, 1944; Parvez, et al, 2006). Also, environmental exposure to $\mathrm{Pb}$ especially through inhalation has been linked to the induction of chromosomal aberrations, cancers and birth defects (Vaglenov, et al, 2001; Valverde, et al, 2002 ).

Occupational and environmental co-exposure to $\mathrm{As}, \mathrm{Pb}$ and other heavy metals have also been documented (Nehez, et al 2000; Englyst, et al 2001). Such exposure has been shown to occur through the consumption of contaminated drinking water and herbal medicine products, inhalation of tobacco smoke and dust and in many occupational settings such as pigments and batteries production, galvanization and recycling of electrical tools (Elias, 1985; Frisbie, et al, 2002; Lambert and Lane, 2004; Saper, et al, 2004). In Nigeria and other West African countries, one of the clear sources of co-exposure to both metals is through the consumption of "calabash chalk". The chalk also known as La Craile, Argile, Nzu, Mabele, Ebumba and Ulo is a banned local drug used by pregnant and nursing mothers to cure morning sickness (NAFDAC, 2006).

A lot evidence abound on the co-exposure to As and $\mathrm{Pb}$ ( Englyst, et al 2001; Lambert and Lane, 2004). However, there is little information on the toxicological consequences of the interaction between the two metals given the fact that metal-metal interactions are important in the toxicity of metals. We therefore describe in this study the effect of dietary co- administration of sodium arsenite and lead acetate in albino rats.

\section{MATERIALS AND METHODS}

\section{Chemicals and Reagents}

Sodium arsenite $\left(\mathrm{Na}_{2} \mathrm{AsO}_{2}\right.$, Mol.wt 129.9 As 57.6\% CAS No 7784-46-5; Sigma Chemical Co., St. Louis, MO) and lead acetate ( $\left(\mathrm{CH}_{3} \mathrm{COO}\right)_{2} \mathrm{~Pb} .3 \mathrm{H}_{2} \mathrm{O}$, mol.wt 379.33, 99.999\%, CAS No. 6080-56-4; Aldrich Chemical Co. Inc. St. Paul Avenue Wisconsin USA) were dissolved in distilled water. 2-3 drops of acetic acid was used to dissolve the lead acetate precipitate. They were administered at a dose of $2.5 \mathrm{mg} / \mathrm{kg}$ body weight (corresponding to $1 / 10$ th of the oral $\mathrm{LD}_{50}$ of sodium arsenite) and $14 \mathrm{mg} / \mathrm{kg}$ body weight (corresponding to $1 / 10$ th of approximate environmental human daily exposure level) (Preston, et al, 1987; Escribano, et al, 1997). All other reagents and chemicals were of analytical grade and were obtained from Sigma Chemical Co. St. Louis, MO. USA.

\section{Experimental Animals}

Twenty twelve-weeks old male albino wistar rats of average weight of approximately $110 \pm 5 \mathrm{~g}$ were purchased from the Physiology Department, University of Ibadan, Ibadan. They were housed in the Experimental Animal House, Department of Biochemistry, University of Ibadan, Nigeria. They were fed with rat pellet containing at least $20 \%$ protein, $3.5 \%$ fat; $9.0 \%$ fibre; $1.2 \%$ calcium; $0.7 \%$ phosphorus; vitamin; mineral per mix; antioxidant; antibiotics; carbohydrates etc. (Ladokun Livestock Feeds Limited, Ibadan, Nigeria) and water ad libitum. The room temperature was $29 \pm 2^{\circ} \mathrm{C}$ with twelve hours light/dark cycle and relative humidity of $60 \pm$ $5 \%$.

\section{Experimental Protocol}

The rats were distributed randomly into four groups of five animals each. The rats in group I served as negative control and were given distilled water throughout the fourteen days of study. Those in group II were given $2.5 \mathrm{mg} / \mathrm{kg}$ body weight of sodium arsenite (SA) only by gavage daily for fourteen days, while those in group III were given only lead acetate (LA; 
$14 \mathrm{mg} / \mathrm{kg}$ body weight) daily also by gavage throughout the duration of the experiment. Animals in group IV were simultaneously fed lead acetate and sodium arsenite daily. All experimental animals had free access to rat pellet and water ad libitum throughout the period of the experiment.

Twenty- four hours after the last treatment with SA and / or LA, all the rats were bled and sacrificed by cervical dislocation. Clastogenic effects were evaluated in the rat bone marrow using the micronucleus assay as described by Heddle and Salmone, (1981) and modified by Heddle, et al, (1981). Two hours prior to sacrifice, the animals were injected (i.p.) with $0.04 \%$ colchicine $(1 \mathrm{ml} / 100 \mathrm{~g}$ body weight). Bone marrow cells from both femurs were used for preparing slides. The slides were fixed, air-dried and pretreated with May-Gruenwald solution. They were then stained with Giemsa solution. The slides were scored for the presence of micronucleated polychromatic erythrocytes (mPCEs) according to standard procedure.

Gamma glutamyl transferase $(\gamma-\mathrm{GT})$ and alkaline phosphatase (ALP) activities were determined in the serum samples using the method of Sazsz, (1969) and Gesellschaft fur Klinische Chemie respectively as described. The activities of alanine amino transferase (ALT) and aspartate amino transferase (AST) were evaluated base on the method of Reitzman and Frankel, (1957) also as described. Basic histopathological examination of the hearts, kidneys, liver and lungs of the test and control rats were done at the Veterinary Pathology Department, University of Ibadan, Ibadan.

\section{Statistical Analysis}

We used One Way Analysis of Variance (ANOVA) at the $\mathrm{P}<0.05$ significant level. If significant differences were found, Duncan's multiple range test was used to compare the significance of differences among the different experimental groups. Significant differences were defined as $\mathrm{P}<0.05$.

\section{RESULTS}

Table 1 shows the frequency of micronucleated polychromatic erythrocytes (mPCEs) induced in the bone marrow cells after the administration of either sodium arsenite (SA) or lead acetate (LA) alone and simultaneously. Sodium arsenite and lead acetate significantly induced mPCEs formation in the bone marrow cells by about 9 and 8 folds respectively as compared with the negative control group $(\mathrm{P}<$ 0.05) in both cases ( Table1, groups I, II, III). Furthermore, co-administration of SA and LA markedly induced mPCEs formation by 22 about folds as compared with the negative control group (Table 1, groups I,IV). When compared with the groups administered SA or LA alone, the induction observed in the co-treatment group was about 2 and 3 folds respectively (Table 1, groups II, III, IV).

The data for the serum activities of $\gamma$-GT, ALT, AST and ALP in the treated and control rats are presented in table 2 . From the data, SA induced the serum activity of ALP $(\approx 3$ folds), ALT $(\approx 2$ folds), $\gamma$-GT $(\approx 2$ folds) and AST $(\approx$ 1fold) respectively as compared with the negative control group (Table 2, groups I and II). Lead acetate induced the activity of ALP by about 2 folds while $\gamma$-GT, AST and ALT were induced by approximately 1 fold respectively also as compared with the negative control (Table 2, groups I and III). Simultaneous feeding of both SA and LA also induced the serum activities of ALP ( $\approx 3$ folds), $\gamma$ - GT ( $\approx 2$ folds), ALT ( $\approx 2$ folds) and AST ( $\approx 1$ fold) respectively as compared with the rats given distilled water only ( Table 2, groups I, IV). The increases in the serum activities of the enzymes observed in the rats co-treated with SA and LA were about 1 fold ( $\gamma$-GT, AST,ALT and ALP respectively) when compared with enzyme activities in the rats fed with SA only ( Table 2, groups II, IV). Also, comparison with rats fed LA alone shows the increases in activities of the enzymes to be about 1 fold ( $\gamma$ GT, AST, ALT) and 2 folds (ALP) respectively (Table2, groups III, IV). 
Table 1:

Induction of micronucleated polychromatic erythrocytes (mPCEs) in rat bone marrow cells after exposure to sodium arsenite and/or lead acetate.

\begin{tabular}{|c|l|l|}
\hline Group & Treatment & $\begin{array}{l}\text { Number of mPCEs/1000 PCEs } \\
(\text { Means } \pm \text { S.E })\end{array}$ \\
\hline I & Distilled Water Only & $0.50^{\mathrm{a}} \pm 0.29$ \\
\hline II & Sodium Arsenite Only & $4.50^{\mathrm{bc}} \pm 0.64$ \\
\hline III & Lead Acetate Only & $4.00^{\mathrm{bc}} \pm 0.91$ \\
\hline IV & Sodium Arsenite + Lead Acetate & $10.75^{\mathrm{d}} \pm 1.25$ \\
\hline
\end{tabular}

Values with the same superscript are not significant at $5 \%$ level whereas values with different superscript are significant $(\mathrm{P}<0.05)$.

Table 2:

Serum level of gamma glutamyl transferase, aspartate amino transferase, alanine amino transferase and alkaline phosphatase in sera of rats.

\begin{tabular}{|c|l|c|c|c|c|}
\hline Group & \multicolumn{1}{|c|}{ Treatment } & $\gamma$-GT & AST & ALT & \multicolumn{1}{c|}{ ALP } \\
\hline I & Distilled water only & $28.10^{\mathrm{a}} \pm 1.21$ & $18.43^{\mathrm{a}} \pm 0.35$ & $22.00^{\mathrm{a}} \pm 0.23$ & $\begin{array}{l}11.56^{\mathrm{a}} \pm \\
0.46\end{array}$ \\
\hline II & Sodium arsenite only & $44.16^{\mathrm{bd}} \pm 1.54$ & $25.75^{\mathrm{bc}} \pm 0.52$ & $\begin{array}{l}41.75^{\mathrm{b}} \pm \\
0.43\end{array}$ & $\begin{array}{l}33.58^{\mathrm{bd}} \pm \\
0.86\end{array}$ \\
\hline III & Lead acetate only & $35.00^{\mathrm{c}} \pm 1.43$ & $22.08^{\mathrm{bc}} \pm 1.07$ & $25.10^{\mathrm{a}} \pm 0.49$ & $\begin{array}{l}18.40^{\mathrm{c}} \pm \\
0.70\end{array}$ \\
\hline IV & $\begin{array}{l}\text { Sodium arsenite }+ \text { Lead } \\
\text { acetate }\end{array}$ & $46.14^{\mathrm{bd}} \pm 2.20$ & $26.40^{\mathrm{bc}} \pm 0.87$ & $\begin{array}{l}35.00^{\mathrm{c}} \pm \\
1.19\end{array}$ & $\begin{array}{l}34.50^{\mathrm{bd}} \pm \\
0.85\end{array}$ \\
\hline
\end{tabular}

Values (mean $\pm \mathrm{SE}$ ) with the same superscript are not significant at $5 \%$ level, whereas values with different superscript are significant at $(\mathrm{P}<0.05)$. $\mathrm{N}=5$ /group.

Result of the basic histopathological study showed that the lungs of the rats fed simultaneously with SA and LA had mild infiltrative heamorrhage. All the other organs (kidney, liver, brain etc ) in this group seem normal. Also, no marked lesions were observed in the organs of the groups II and III rats as compared with the organs from the negative control rats in group I.

\section{DISCUSSION}

This study was designed primarily to assess the effect of co-exposure to arsenic and lead in rats. The results of the study clearly demonstrate that sodium arsenite and lead acetate when administered alone significantly $(\mathrm{P}<0.05)$ induced the formation of micronuclei in the polychromatic erythrocytes (PCEs) of the rat bone marrow cells (Table 1). This observation is consistent with an earlier observation and those of others on the genotoxic potentials of SA and LA in the bone marrow and other tissues (Moore, et al, 1993; Vaglenov, et al, 2001; Valverde, et al, 2002; Odunola, 2003; Poma, et al, 2003; Celik, et al, 2005). In this particular investigation, the induction by SA (at $1 / 10^{\text {th }}$ of the $\mathrm{LD}_{50} ; 2.5 \mathrm{mg} / \mathrm{kgbw}$ ) and LA (at $1 / 10^{\text {th }}$ of the approximate environmental daily exposure in man; $14 \mathrm{mg} / \mathrm{kg}$ ) was about 9 and 8 folds respectively as compared with the micronucleated polychromatic erythrocytes (mPCEs) induced in the bone marrow of rats given distilled water alone (Table 1, groups I, II, III).

Simultaneous administration of SA and LA also significantly induced mPCEs formation in the bone marrow of the rats $(\mathrm{P}<0.05)$. This induction was about 22 folds when compared with mPCEs induced in the negative control group. (Table 1, groups I, IV). Furthermore, the 
induction observed after co-administration of the two compounds appears to be synergistic. This suggests that simultaneous administration or coexposure to As and $\mathrm{Pb}$ may result in an enhancement of the toxic effects of both metals. It had earlier been shown that co-administration of $\mathrm{Pb}$ and the pyrethroid cypermethrin results in an enhanced genotoxic effect in rat bone marrow cells (Nehez, et al, 2000). Disturbances in intracellular calcium by As and/or $\mathrm{Pb}$ may be one of the mechanisms involved in mPCEs induction by the two metals (Goldstein, 1993; Liu and Huang, 1997; Florea, et al, 2005).

Given the concentration of SA and LA used in this study, the observations made further suggest that greater health hazards that may result from co-exposure to $\mathrm{As}$ and $\mathrm{Pb}$ at levels not exceeding their permissible levels cannot be under estimated. For instance, in addition to the observed genotoxic effects, it has been suggested that a possible interaction between $\mathrm{As}$ and $\mathrm{Pb}$ may be involved in lung cancer risks among lead smelter workers simultaneously exposed to arsenic (Englyst, et al, 2001). In this connection, pregnant/nursing mothers and their new-borns in Nigeria and other West African countries may be at greater risk of exposure to $\mathrm{As}$ and $\mathrm{Pb}$ from the consumption of calabash chalk and As contaminated drinking water. This may be closely linked to the incidence of maternal and infant mortality in these populations. It is known that lead retained in hard tissues after exposure can be metabolized during pregnancy, lactation and other pathological conditions. (Silbergeld, et al 1988; Silbergeld, 1991).

The results obtained from the assessment of the serum activities of $\gamma$-GT, ALP, ALT and AST show that SA and LA separately induce the serum activity of $\gamma$-GT significantly $(\mathrm{P}<0.05)$ by about 2 and 1 folds respectively as compared with the $\gamma$-GT activity induced in the control rats (Table 2; groups I, II, III). Simultaneous administration of both compounds also significantly induced serum $\gamma$-GT activity by about 2 folds also as compared with the negative control (Table 2; groups I, IV). This is an indication of induction of hepatotoxicity and oxidative stress in the hepatocytes. Increased activity of $\gamma$ - GT has been associated with hepatotoxicity, oxidative stress and chromosomal abberations in cells (Dinari, et al, 1979; Karmaker, et al, 1999; Lee, et al, 2004). SA and LA also induce the serum activity of ALP following the same pattern as observed for $\gamma$-GT. SA and LA significantly $(\mathrm{P}<0.05)$ induced ALP activity separately by about 3 and 2 folds respectively while co-administration of the two compounds caused about 3 folds induction all as compared with the negative control group (Table 2). Exposure to SA had been shown to induce ALP activity (Chattopady, et al, 2003).

Taken together, SA induced the serum activity of AST and ALT by about 1 and 2 folds while the induction by LA was about I fold each as compared with the induction observed in group I rats given distilled water alone. Simultaneous feeding of both SA and LA caused an elevation of about 1 and 2 folds in AST and ALT activities respectively (Table 2). The induction of AST and ALT activities following exposure to As has been documented (Mallick, et al, 2003). Basic histopathological analysis of the organs from the rats after sacrifice showed that rats fed simultaneously with SA and LA had mild infiltrative hemorrhage in their lungs. All the other organs seem normal. The effect of long term co-exposure of laboratory animals to arsenic and lead is being studied.

\section{REFERENCES}

Abernathy, C.O, Liu Y.P, Long Fellow D, Aposhian, H.V, Beck, B, Fowler, B, Goyer, R, Menzer, R., Rossman, T, Thompson, $C$ and Waalkes, M. (1999) Arsenic: Health effects, Mechanism of actions and research issue Environ. Health. Perspect. 107: 593-597.

Celik, A., Ogenler, O. and Comelekoglu, U. (2005). The evaluation of micronucleus frequency by acridine orange fluorescent staining in peripheral blood of rats treated with lead acetate. Mutagenesis 20(6): 411-415.

Chattopady, S., Sampa, P., Ghosh, D.M. and Jogen, (2003). Effect of dietary co-administration of sodium - selenite on sodium arsenite - induced ovarian and uterine disorders in mature albino rats. Toxicol. 75: 412-422. 
Dinari, G., Cohen, M.I. McNamara, H. and Kochen, J.A. (1979). Effect of lead exposure on the activity of some hepatic enzymes in rat. Pediatr. Res. (5Ptl): 644-646.

Elias, R.W. (1985). Lead exposure in human environment. In Mahaffey, K. Dietary and environmental lead. Human health effects, Elsevier Amsterdarm-New York-Oxford. pp 79-107.

Englyst, V, Lundstrom, N.G., Gerhandsson, L, Rylander, L, and Nordberg, G. (2001) Lung cancer risks among lead smelter workers also exposed to arsenic. Sci. Total Environ. 273(1-3): 77-82.

Escribano, A., Revilla, M; Hernandez, E.R., Seco, C., Gonzalez-Riola, J., Villa, L.F. and Rico, H. (1997). Effect of lead on bone development and bone mass: a morphometric, densitometric and histomorphometric study in growing rats. Calcif. Tissue Int. 60: 200-203.

Florea, A.M., Yamoah, E.N. and Dopp, E. (2005). Intracellular calcium disturbances induced by arsenic and its methylated derivatives in relation to genomic damage and apoptosis induction. Environ. Health. Perspect. 113(6): 659-664.

Frisbie, S.H., Ortega, R., Maynard, D.M. and Sarkar, B. (2002). The concentration of arsenic and other toxic elements in Bangladesh's drinking water. Environ. Health Perspect. 110: 1147-1153. Goldstein, G.W. (1993). Evidence that lead act as a calcium substitute in second messenger metabolism. Neurotoxicol. 14: 97-102.

Heddle, J.A. and Salmone, M.F. (1981). The micronucleus assay I: In vivo. In Stich, H.F. and San, R.H.C. eds. Topics in environmental physiology and medicine. Short term tests for chemical carcinogens. Springer-Verlag, New York Heidelberg, Berlin. pp. 243-249.

Heddle, J.A. Sudharsan, R.A. and Krepinsky, A.B. (1981). The micronucleus assay II: In vitro. In: Stich, H.F and San, R.H.C. eds. Topics in environmental physiology and medicine. Short term tests for chemical carcinogens. SpringerVerlag, New York, Heidelberg, Berlin. pp. 250254.

Karmaker, R., Banerjee, A., Datta, S. and Chatterjee, M. (1999). Influence of cadmium intoxification on hepatic lipid peroxidation, glutathione level and glutathioneS-transferase and gamma-glutamyl transpeptidase activities: Correlation with chromosome aberration in bone marrow cells. J. Environ. Pathol. Toxicol. Oncol. 18: 277-287.

Lambert and Lane. (2004). Lead, arsenic and PAH in soil and house dust. Environ. Health Perspect. 112: 39-41.

Lee, D.H., Blomhoff, R. and Jacobs, D.R. (2004). Is serum gamma glutamyl transferase a maker of oxidative stress? Free Radic. Res. 38: 535-539.

Liu, Y.C. and Huang, H. (1997). Involvement of calcium dependent protein kinase in arseniteinduced genotoxicity in Chinese hamster ovary cells. J. Cell Biochem. 64: 423-433.

Mallick, P., Mallick, J.C., Guha, B. and KhudaBukhsh, A.P. (2003). Ameliorating effect of micodoses of potentizes homeopathicdrug, arsenic album, on arsenic-induced toxicity in mice. BMC Complementary and Alternative Medicine. 3: 7.

Moore, L.E.; Smith, A.H.; Hopenhayn-Rich. (1997). Micronuclues in exfoliated bladder cells among individuals chronically exposed to arsenic in drinking water. Cancer Epidemiol. Biomarkers Rev. 6: 1-6.

NAFDAC (2006). www.nafdacnigeria.org

Nehez, M.; Lorencz, R. and Desi, I. (2000). Simultaneous action of cypermethrin and two environmental pollutant metals, cadmium and lead, on bone marrow cell chromosomes of rats in subchronic administration. Ecotoxicol. Environ. Saf. 45: 55-60.

Odunola, O.A. (2003). Comparative effects of some local food condiments on sodium arsenite induced clastogenicity. Afr. J. Med. Med. Sci. 32: 75-80.

Parvez, F.; Chen, Y.; Maria, A.; Hussain, A.I; Hassina, M.; Dhar, R.; Geen, A.; Graziano and Ahsan, H. (2006). Prevalence of arsenic exposure from drinking water and awareness of its health risks in a Bangladeshi population; results from a large population-based study. Environ. Health Perspect. 114(3): 355-359.

Poma, A.; Pittaluga, E.; Tucci, A. (2003). Lead acetate genotoxicity on human melanoma cells in vitro. Melanoma Res. 13(6): 563-566.

Preston, R.J., Dean, B.J.; Galloway, S; Hoden, H.; McFee, A.F. and Shelby, M. (1987). Mammalian in vivo cytogenetic assays: Analysis of chromosome aberrations in bone marrow cells. Mutat. Res. 189: 157-165.

Reitman and Frankel, S.A. (1957). Colorimetric method for determination of serum glutamic 
oxaloacetic and glutamic pyruvic transaminase. Am. J. Clin. Patho. 28: 56-63.

Saper, R.B.; Kales, S.N.; Paquin, J.; Burns, M.J.; Eisenberg, D.M.; Davis, R.B. and Phillips, R.S. (2004) Heavy metal content of Ayurvedic herbal medicine products. JAMA 292: 2868-2873. Silbergeld, E.K. (1991). Lead in bone: implications for toxicology during pregnancy and lactation. Environ. Health Perspect. 91: 63-70.

Silbergeld, E.K.; Schwartz, J. and Mahaffey, K.R. (1988). Lead and osteoporosis mobilization of lead from bone in post menopausal women. Environ. Res. 47: 79-94.

Szasz, G. (1969). A kinetic photometric method for serum gamma glutamyl transferase. Clin. Chem. 124: 124-136.

Vaglenov, A; Greus, A; Laltchev, S; Petkova, V; Pavlova, S. and Marcos, R. (2001). Occupational exposure to lead and induction of genetic damage.
Environ Health Perspect. 109: 205-298.

Valentine, J.L. (1994). Review of health assessments for US/Canada populations exposed to arsenic in drinking water. In: Arsenic Exposure and Health (a special issue of Environmental Geochemistry and Health, Vol.16) (Chappell, W.R., Abernathy, C.O., Cothern, C.R., eds). Surrey, UK: Laws and Stimson Associates. Pp: 139-152.

Valverde, M; Fertoul, T.I; Diaz-Barriga, F; Mejia, J. and de"Castillo, E.R. (2002). Genotoxicity induced in CD-1 mice by inhaled lead: differential organ response. Mutagenesis, 17(1), 55-61. 